\title{
Efficacy of Telecardiology in improving the results of Cardiac Rehabilitation after acute myocardial infarction
}

\section{Efficacia della Telecardiologia nel migliorare i risultati della Riabilitazione Cardiologica dopo IMA}

\author{
Francesco Giallauria, Rosa Lucci, Francesco Pilerci, Anna De Lorenzo, \\ Athanasio Manakos, Marianna Psaroudaki, Mariantonietta D'Agostino, \\ Alessandra Vitelli, Luigi Maresca, Domenico Del Forno, Carlo Vigorito
}

\begin{abstract}
Efficacy of Telecardiology in improving the results of Cardiac Rehabilitation after acute myocardial infarction. F. Giallauria, R. Lucci, F. Pilerci, A. De Lorenzo, A. Manakos, M. Psaroudaki, M. D'Agostino, A. Vitelli, L. Maresca, D. Del Forno, C. Vigorito.

Background: This study was addressed to verify if Telecardiology (TC) improves the results of Cardiac Rehabilitation in patients following a home-based Cardiac Rehabilitation Program (CRP) after acute myocardial infarction (AMI).

Materials and Methods: We studied three groups of patients after AMI: Group A (control group): 15 patients, who followed a standard in-hospital CRP of 3 weekly sessions of 2 months duration; Group B (study group): 15 patients, who were enrolled in a home-based CRP of similar duration and were monitored by TC with the aid of an ecg-device (Sorin Life Watch CG 6106); Group C (second control group): 15 patients, who followed a home-based CRP without ecgmonitoring by TC. All patients performed a symptom-limit-
\end{abstract}

ed exercise testing at the beginning of the CRP. Psychometric data (STAI-Y1, STAI-Y2, BDI) were also evaluated. At the end of the CRP all patients underwent repeated exercise testing and psychometric evaluation.

Results: TC applied to the home-based CRP was associated with a good compliance to the program. Compared to Group C, in Group B we observed an increase of maximal heart rate, exercise duration, maximal work-load, and an improvement of anxiety, a trend to reduction of depression, and an improvement of quality of life. These results were very similar to Group A patients following a hospital-based CRP. Conclusions: TC improves compliance, functional capacity and psychological profile of patients undergoing a home-based CRP, compared to patients enrolled in a homebased CRP without ecg-monitoring by Telecardiology.

Keywords: cardiac rehabilitation, telecardiology, myocardial infarction.

Monaldi Arch Chest Dis 2006; 66: 8-12.

Department of Clinical Medicine, Cardiovascular and Immunological Sciences. Cardiac Rehabilitation Unit. University of Naples Federico II, via S. Pansini 5, 80131 Napoli (Italy).

Corresponding author: Francesco Giallauria, MD; Department of Clinical Medicine, Cardiovascular and Immunological Sciences. Cardiac Rehabilitation Unit. University of Naples Federico II, Via S. Pansini 5, 80131 Napoli (Italy); E-mail address: vigorito@unina.it

\section{Introduction}

Comprehensive Cardiac Rehabilitation includes a series of interventions aimed at improving functional recovery and quality of life after acute myocardial infarction (AMI) [1-4]. Several studies have shown that a comprehensive program of Cardiac Rehabilitation (CR), that includes physical training, psychological intervention, behavioural and pharmacological interventions impacting on risk factors for atherosclerosis (stop-smoking, control of hypertension and diabetes, reducing LDL cholesterol) is successful in reducing mortality and morbidity after AMI, and also in improving functional capacity, psychological profile and quality of life [5-9]. The ideal length of the program should be at least 8 weeks, with subsequent follow up. One of the main problems of CR is, however, the difficulty of its application to the whole population of AMI, often due to logistic problems impeding the patient to reach the hospital to follow a 8 week outpatient program under cardiological supervision. These patients often continue at home an exercise program given at discharge, but, due to few contacts with the referring hospital, lose the beneficial effects of CR at mediumlong term. Telecardiology may at least in part reduce these logistic problems through the utilization of devices, nowadays widely applied in several areas of cardiology, allowing patients to maintain contact and feedback with the referral hospital even at home [1013]. The aim of this study was to assess the efficacy of telecardiology in improving adhesion to exercise prescription, functional capacity and psychological profile of patients following a home-based Cardiac Rehabilitation Program (CRP) after AMI.

\section{Materials and Methods}

\section{Patient population}

Patient population was composed of 45 patients, subdivided in three subgroups, who were similar in 
demographic characteristics and clinical presentation (table 1). All patients had survived a recent AMI within the last 8 days. We excluded patients with heart failure, residual myocardial ischemia, severe ventricular arrhythmias, atrial fibrillation, disability or cognitive compromise. Patients were subdivided in 3 subgroups: group A (control group): 15 patients, who followed a standard in-hospital 8weeks CRP with 3 weekly sessions, monitored by a cardiologist; Group B (study group): 15 patients, who couldn't follow an in- hospital CRP because of logistic problems, and were enrolled in a 8-weeks home-based CRP with telecardiology monitoring; Group C (second control group): 15 patients who also couldn't follow a hospital-based CRP, and who followed a home-based CRP without ecg-monitoring by telecardiology. Group B and C were enrolled if they had a cyclette available at home.

\section{Study Protocol}

Before initiating CRP all patients underwent clinical examination, routine non invasive cardiologic tests and a symptom-limited exercise test. At the beginning of the CRP they also filled a questionnaire to evaluate their psychological status: anxiety through STAI-Y1 (State anxiety) and STAI-Y2 (trait scale of anxiety inventory), depression through BDI (Beck Depression Inventory) and quality of life through MOS/SF-36 (Medical Outcomes Study 36-Item Short-Form Health Survey). Standard CRP included exercise training, functional and prognostic evaluation, risk factors assessment, educational and behavioural intervention, pharmacologic control, as indicated in the International Guidelines [1]. The exercise program followed by group A patients consisted in 3 weekly out-patient sessions of 30 min cycling at a work load of $75 \%$ of peak heart rate (HR) reached at exercise stress test performed before the onset of exercise training. Patients of group $\mathrm{B}$ and $\mathrm{C}$ received instruction to follow a home based training similar to that followed in hospital by group A patients. They were instructed to exercise 3 times/week for $30 \mathrm{~min}$ on their cyclette at home, and were instructed to measure their HR to achieve the target HR (about $75 \%$ of peak HR achieved at baseline exercise stress test). A simple recording-transmitting ecg-device (Sorin Life Watch CG 6106) was given to Group B patients.
Thanks to this system it was possible to monitorize the ecg of patients during home-based exercise program. This device was connected to the body with electrodes and allowed ecg recording at baseline an during exercises. Thereafter, the ecg was transmitted to a Call Center by home-telephone and subsequently sent to our Center by e-mail in a few minutes time. The training sessions were performed in days and hours predetermined and agreed with each patient. Patients were seen after two months, at the end of the exercise program, for re-evaluation of clinical state, and for repetition of psychometric evaluation and of a symptom-limited exercise testing.

\section{Results}

No patient of Group B was lost at follow-up, while in groups $\mathrm{A}$ and $\mathrm{C}$ we lost two patients at follow-up. None of the patients of group B needed hospitalization during follow-up while in Group A and group $\mathrm{C}$ two patients required hospitalization. In Group B patients we observed an improvement of cardiovascular functional capacity at the end of CRP, with an increase in peak exercise HR, exercise duration, and peak exercise work-load ( $\mathrm{p}<0.05$, PreCR vs Post-CR; $p<0.01$ ) (table 2). Similar improvement were observed in Group A ( $p<0.05$, Pre-CR vs Post-CR), but not in Group C patients ( $\mathrm{p}=\mathrm{ns}$, Pre-CR vs Post-CR) (table 2). Table 3 shows the results of psychological status evaluation and suggests that in group B there was an improvement of state anxiety and a trend to a reduction of depression, compared to Group $\mathrm{C}$ patients. The evaluation of parameters reflecting quality of life (MOS/SF-36) showed no modification in $8 / 15$ patients and an improvement in $2 / 15$ patients in group $B$, while there was a worsening in $7 / 15$ patients and an improvement in 1 patient in group $\mathrm{C}(\mathrm{p}<0.05)$.

\section{Discussion}

Cardiac Rehabilitation aims at facilitating physical, psychological and emotional recovery after AMI [1]. This is achieved through hospitalbased comprehensive programs including exercise training, patient education and counselling, optimal pharmacological treatment, and psychological intervention. Meta-analyses of the effectiveness of

Table 1. - Demographic and clinical characteristics of study patients

\begin{tabular}{lccc}
\hline & $\begin{array}{c}\text { Group A } \\
\mathbf{n}=\mathbf{1 5}\end{array}$ & $\begin{array}{c}\text { Group B } \\
\mathbf{n}=\mathbf{1 5}\end{array}$ & $\begin{array}{c}\text { Group C } \\
\mathbf{n}=\mathbf{1 5}\end{array}$ \\
\hline Age (M \pm SD) & $54 \pm 8$ & $60 \pm 6$ & $58 \pm 6$ \\
Gender (M/F) & M & M & M \\
SBP (mmHg) & $133 \pm 26$ & $128 \pm 18$ & $131 \pm 21$ \\
Diabetes & $5 / 15$ & $3 / 15$ & $3 / 15$ \\
Smokers & $12 / 15$ & $12 / 15$ & $10 / 15$ \\
Total Cholesterol (mg/dl) & $196 \pm 24$ & $194 \pm 27$ & $200 \pm 28$ \\
AMI anterior & $12 / 15$ & $11 / 15$ & $13 / 15$ \\
PTCA & $13 / 15$ & $13 / 15$ & $12 / 15$ \\
LVEF (\%) & $35 \pm 6$ & $31 \pm 9$ & $34 \pm 8$ \\
Onset of Cardiac Rehabilitation (day from AMI) & 7 & 8 & 7 \\
\hline
\end{tabular}


Table 2. - Cardiovascular functional capacity before and after Cardiac Rehabilitation (CR)

\begin{tabular}{|c|c|c|c|c|c|c|}
\hline & \multicolumn{2}{|c|}{ GROUP A $(n=15)$} & \multicolumn{2}{|c|}{ GROUP B $(n=15)$} & \multicolumn{2}{|c|}{ GROUP C (n=15) } \\
\hline & Pre-CR & Post-CR & Pre-CR & Post-CR & Pre-CR & Post-CR \\
\hline Exercise duration (min) & $3.6 \pm 1.2$ & $4.6 \pm 2.2 *$ & $5.8 \pm 2.1$ & $7.6 \pm 2.5^{*}, * *$ & $3.2 \pm 1.4$ & $3.8 \pm 1.2$ \\
\hline Heart Rate max (\% max predicted) & $65 \pm 9.2$ & $82 \pm 8.8^{*}$ & $73 \pm 12.4$ & $85 \pm 13.8 *, * *$ & $69 \pm 10.6$ & $76 \pm 11.3$ \\
\hline Max-work load (Watts) & $94 \pm 16.4$ & $112 \pm 22.4 *$ & $100 \pm 24.5$ & $123 \pm 20.7 * * *$ & $80 \pm 16.2$ & $86 \pm 13.5$ \\
\hline
\end{tabular}

Table 3. - Psychological profile before and after Cardiac Rehabilitation (CR)

\begin{tabular}{lcccccc}
\hline & \multicolumn{2}{c}{ GROUP A $(\mathbf{N}=15)$} & \multicolumn{2}{c}{ GROUP B $(\mathbf{N}=15)$} & \multicolumn{2}{c}{ GROUP C $(\mathbf{N}=15)$} \\
\cline { 2 - 7 } & Pre-CR & Post-CR & Pre-CR & Post-CR & Pre-CR & Post-CR \\
\hline STAI-Y1 & $39 \pm 5$ & $36 \pm 6$ & $37 \pm 5.33$ & $33.8 \pm 7.52 *$ & $40.5 \pm 6.26$ & $38 \pm 7.07$ \\
STAI-Y2 & $34 \pm 5$ & $35 \pm 7$ & $33.4 \pm 6.3$ & $33 \pm 8.7$ & $33.5 \pm 6.4$ & $35.5 \pm 12$ \\
BDI & $15.1 \pm 5$ & $16.4 \pm 3$ & $16.2 \pm 4.5$ & $15.8 \pm 2.2 *$ & $14.5 \pm 0.7$ & $18 \pm 4.24$ \\
\hline$*$ p $<0.05$, Group B Pre-CR vs Post-CR. & & & & &
\end{tabular}

these programs suggest that they can achieve a reduction in cardiac mortality of $20-26 \%$ over a $1-3$ year time [2-4]. CRP are also associated with improvement in aerobic capacity [14], reduction of risk profile [15], improvement in lipoprotein patterns [5], psychological status and quality of life [16-18]. It is clear that many patients who could benefit from cardiac rehabilitation are not enrolled in these programs due to both service and patient factors. Enrolment rates for Cardiac Rehabilitation have been reported to range from 15-59\% [19]. Many services concentrate on relatively low risk, white middle aged patients, while women [20,21] and elderly are less likely to be included [22-24]. Poor recruitment is also related to service factors, such as the availability and accessibility of a program [25], the strength of a physician's recommendation to attend [26-28] and treatment by a general physician, rather than a cardiologist. Patient factors include the reported feeling amongst the elderly and women that they will be out of place [29] and beliefs about whether their illness was amenable to cure or control [30]. Socio-demographic factors such as deprivation [31], level of education [32] and spouse involvement [33, 34] are also significant predictors of enrolment. Of those patients who do attend hospital Cardiac Rehabilitation the dropout rates from exercise programs range from $20 \%$ in the first three months to $50 \%$ at 6 months to a year [35]. Smokers, patients who have had more that one myocardial infarction $[36,37]$, and women are more likely to drop out [38]. Therefore it is important to device new strategies to improve patients enrolment in CRP in order to extend their benefits also to patients unable to attend hospital sessions for logistic or other reasons. One possibility is offered by the prescription of a home-based CRP, allowing patients to follow physical training in their home environment. However, it is also equally important to ensure complete and continued patients adhesion to suggested home-based programs. Trials comparing home-based Cardiac Rehabilitation programmes to usual care (patients not enrolled in Cardiac Rehabilitation) have reported significantly greater improvements in exercise capacity, systolic blood pressure and lower anxiety in the patients participating in home rehabilitation compared to the controls at follow-up [39]. Eight randomised controlled trials comparing homebased to supervised centre-based CRP have been published [40-47]. These studies report similar improvements in exercise capacity, systolic blood pressure or serum cholesterol at follow-up between the home and centre-based groups. The present study shows that patients following home-based CRP had similar benefits of patients following hospital-based programs. In our experience, a homebased exercise prescription without TC monitoring was not successful in improving CRP end-points. In our population the motivations to follow prescribed exercise training at home was not enough to sustain an 8 week home-based program, but the addition of a simple ecg device such that used in our study was sufficient to achieve the same results of hospital-based CRP.

In conclusion, TC improved compliance and results of a home-based CRP, in particular functional capacity and psychology profile, compared to patients enrolled in a home-based CRP without ecgmonitoring by TC. TC is helpful improving adhesion to home-based Cardiac Rehabilitation in those patients unable to attend in-hospital program for logistic reasons. The possibility to extend this model of assistance out of hospital could enhance enrolment in CRP and allow the application of its benefits to a large number of patients after AMI. 


\section{Riassunto}

Introduzione: Scopo del seguente lavoro è verificare se la Telecardiologia (TC) migliora i risultati della Riabilitazione Cardiologica in pazienti arruolati in un programma di Riabilitazione Cardiologica (PRC) domiciliare dopo infarto acuto del miocardio (IMA).

I pazienti sono stati suddivisi in tre gruppi: gruppo A (controllo): 15 pazienti che seguivano un PRC standard ospedaliero di tre sedute settimanali della durata di 8 settimane; gruppo B (intervento): 15 pazienti arruolati in un PRC domiciliare e monitorati tramite l'ausilio della TC utilizzando un dispositivo che registra l'elettrocardiogramma (Sorin Life Watch CG 6106); gruppo C (secondo gruppo di controllo): 15 pazienti che seguono un PRC domiciliare senza monitoraggio ecg tramite TC. Tutti i pazienti hanno eseguito un test ergometrico limitato da sintomi all' inizio del PRC. Sono stati inoltre valutati $i$ dati psicometrici (STAI-Y1, STAI-Y2, BDI). Al termine del PRC i pazienti hanno ripetuto il test ergometrico e la valutazione psicometrica.

Risultati: La TC applicata al PRC domiciliare è associata ad una buona compliance al programma. Rispetto al gruppo C nel gruppo B abbiamo osservato più alti valori della frequenza cardiaca massimale, della durata di esercizio, del carico massimo di lavoro, ed un miglioramento dello stato d'ansia, un trend in riduzione dello stato depressivo con un miglioramento della qualità di vita. I risultati del gruppo B erano simili a quelli del gruppo A che svolgevano un programma tradizionale ospedaliero.

Conclusioni: La TC applicata ad un PRC domiciliare risulta in un miglioramento dell' adesione, della capacità funzionale e del profilo psicologico dei pazienti, in particolare rispetto ai quelli arruolati in PRC domiciliare senza monitoraggio ecg tramite TC.

Parole chiave: riabilitazione cardiologica, telecardiologia, infarto del miocardio.

Acknowledgements: We thank Mr Mario Rosario Eliseo, Mr. Mario Aurino, and Mrs. Maria Calabrese for their technical support.

\section{CAPTIONS}

AMI: Acute Myocardial Infarction

CRP: Cardiac Rehabilitation Program

PTCA = percoutaneous transluminal coronary angiography

$\mathrm{LVEF}=$ left ventricular ejection fraction

TC: Telecardiology

HR: Heart Rate

STAI-Y1: State Anxiety

STAI-Y2: Trait Scale of Anxiety Inventory

BDI: Beck Depression Inventory

$\mathrm{SBP}=$ systolic blood pressure

MOS/SF-36 = Medical Outcomes Study 36-Item Short-Form Health Survey

\section{References}

1. Ades PA. Cardiac Rehabilitation and secondary prevention of coronary heart disease. $N$ Engl J Med 2001; 345: 892-902.

2. O'Connor GT, Buring JE, Yusuf S, Goldhaber SZ, Olmstead EM, Paffenbarger RS Jr, Hennekens CH. An overview of randomized trials of rehabilitation with exercise after myocardial infarction. Circulation 1989; 80: 234-244.
3. Oldridge NB, Guyatt GH, Fischer ME, Rimm AA. Cardiac rehabilitation after myocardial infarction. Combined experience of randomized clinical trials. JAMA 1988; 260: 945-950.

4. Jolliffe J, Rees K, Taylor R, Thompson D, Oldridge N, Ebrahim S. Exercise-based rehabilitation for coronary heart disease [Cochrane review]. Exercise-based rehabilitation for coronary heart disease. Cochrane Database Syst Rev 2000; [4]: CD001800. Review. Update in: Cochrane Database Syst Rev 2001; [1]: CD001800.

5. Crouse SF, O'Brien BC, Grandjean PW, Lowe RC, Rohack JJ, Green JS. Training intensity, blood lipids and apolipoproteins in men with high cholesterol. J Appl Physiol 1997; 82: 270-277.

6. Fletcher GF. The antiatherosclerotic effect of exercise and development of an exercise prescription. Cardiol Clin 1996; 14: 85-95.

7. Yu CM, Lau CP, Chau J, McGhee S, Kong SL, Cheung BM, Li LS. A short course of cardiac rehabilitation program is highly cost effective in improving long-term quality of life in patients with recent myocardial infarction or percutaneous coronary intervention. Arch Phys Med Rehabil 2004 Dec; 85: 1915-1922.

8. Ades PA, Green NM, Coello CE. Effects of exercise and cardiac rehabilitation on cardiovascular outcomes. Cardiol Clin 2003 Aug; 21: 435-448.

9. Taylor RS, Brown A, Ebrahim S, Jolliffe J, Noorani H, Rees K, Skidmore B, Stone JA, Thompson DR, Oldridge N. Exercise-based rehabilitation for patients with coronary heart disease: systematic review and meta-analysis of randomized controlled trials. Am J Med 2004 May 15; 116: 682-692.

10. Scalvini S, Giordano A, Glisenti F. Telecardiology: a new way to manage the relation between hospital and primary care. Monaldi Arch Chest Dis 2002; 58: 132-134.

11. Shaw DK, Sparks KE, Jennings HS 3rd, Vantrease JC. Cardiac rehabilitation using simultaneous voice and electrocardiographic transtelephonic monitoring. Am J Cardiol 1995; 76: 1069-1071.

12. Squires RW, Miller TD, Harn T, Micheels TA, Palma TA. Trantelephonic electrocardiographic monitoring of cardiac rehabilitation exercise sessions in coronary artery disease. Am J Cardiol 1991; 67: 962-964.

13. Shaw DK, Sparks KE, Jennings HS $3^{\text {rd }}$. Transtelephonic exercise monitoring: a review. I Cardiopulm Rehab 1998; 18: 263-270.

14. Fattirolli F, Cellai T, Burgisser C. Physical activity and cardiovascular health a close link. Monaldi Arch Chest Dis 2003 Mar; 60: 73-78.

15. Savage PD, Brochu M, Poehlman ET, Ades PA. Reduction in obesity and coronary risk factors after high caloric exercise training in overweight coronary patients. Am Heart J 2003; 146: 317-323.

16. Linden W, Stossel C, Maurice J. Psychosocial interventions for patients with coronary artery disease: a metaanalysis. Arch Intern Med 1996; 156: 745-752. Erratum in: Arch Intern Med 1996; 156: 2302.

17. Hemingway H, Marmot M. Evidence based cardiology: psychosocial factors in the aetiology and prognosis of coronary artery disease. Systematic review of prospective cohort studies. BMJ 1999; 318: 1460-1467.

18. Black JL, Allison TG, Williams DE, Rummans TA, Gau GT. Effect of intervention for psychosocial distress on rehospitalization rates in cardiac rehabilitation patients. Psychosomatics 1998; 39: 134-143.

19. Andrew GM, Oldridge NB, Parker JO, Cunningham DA, Rechnitzer PA, Jones NL, Buck C, Kavanagh T, Shephard RJ, Sutton JR. Reasons for dropout from exercise programs in post-coronary patients. Med Sci Sports Exerc 1981; 13: 164-168.

20. Ades PA, Waldmann ML, Polk DM, Coflesky JT. Referral patterns and exercise response in the rehabilitation of female coronary patients aged greater than or equal to 62 years. Am J Cardiol 1992; 69: 1422-1425. 
21. Moore SM, Kramer FM. Women's and men's preferences for cardiac rehabilitation program features. J Cardiopulm Rehab 1996; 16: 163-168.

22. Ades P, Waldmann M, Guillespie C. A controlled trial of exercise training in older coronary patients. J Gerontol A Biol Sci Med Sci 1995; 50[A]1: M7-M11.

23. Ades PA, Waldmann ML, McCann WJ, Weaver SO. Predictors of cardiac rehabilitation in older coronary patients. Arch Intern Med 1992; 152: 1033-1035.

24. Gori P, Pivotti F, Mase N, Zucconi V, Scardi S. Compliance with cardiac rehabilitation in the elderly. Eur Heart $J$ 1984: 5[suppl. E]: 109-111.

25. Stiller JJ, Holt MM. Factors influencing referral of cardiac patients for cardiac rehabilitation. Rehabil Nurs 2004 Jan-Feb; 29: 18-23.

26. Burns KJ, Camaione DN, Froman RD, Clark BA 3rd. Predictors to referral to cardiac rehabilitation and cardiac exercise self-efficacy. Clin Nurs Res 1998; 7: 147-163.

27. Hlatky MA, Cotugno HE, Mark DB, O'Connor C, Califf RM, Pryor DB. Trends in physician management of uncomplicated acute myocardial infarction, 1970 to 1987. The American Journal of Cardiology 1988 Mar 1; 61: 515-8.

28. Grace SL, Evindar A, Abramson BL, Stewart DE. Physician management preferences for cardiac patients: factors affecting referral to cardiac rehabilitation. Can J Cardiol 2004; 20: 1101-1107.

29. Campbell N, Grimshaw J, Rawles J, Ritchie L. Cardiac rehabilitation: the agenda set by post-myocardial infarction patients. Health Educ J 1994; 53: 409-420.

30. Petrie K, Weinman J, Sharpe N, Buckley J. Role of patients' view of their illness in predicting return to work and functioning after myocardial infarction: longitudinal study. BMJ 1996; 312: 1191-1194.

31. Pell J, Pell A, Morrison C, Blatchford O, Dargie H. Retrospective study of influence of deprivation on uptake of cardiac rehabilitation. BMJ 1996; 313: 267-268.

32. Harlan WR 3rd, Sandler SA, Lee KL, Lam LC, Mark DB. Importance of baseline functional and socioeconomic factors for participation in cardiac rehabilitation. Am J Cardiol 1995; 76: 36-39.

33. Karner AM, Dahlgren MA, Bergdahl B. Rehabilitation after coronary heart disease: spouses' views of support. $J$ Adv Nurs 2004; 46: 204-211.

34. Dracup K, Meleis AI, Clark S, Clyburn A, Shields L, Staley M. Group counselling in cardiac rehabilitation: effect on patient compliance. Patient Educ Couns 1984; 6: 169-177.

35. Oldridge, $\mathrm{N}$ : Compliance and exercise in primary and secondary prevention of coronary heart disease: a review. Prev Med 1982; 11: 56-70.

36. Lee J, Jensen B, Oberman A, Fletcher B, Raczynski J. Adherence in the training levels comparison trial. Med Sci Sports Exerc 1996; 28: 47-52.
37. Fletcher GF, Balady G, Blair SN, Blumenthal J, Caspersen C, Chaitman B, Epstein S, Sivarajan Froelicher ES, Froelicher VF, Pina IL, Pollock ML. Statement on exercise: benefits and recommendations for physical activity programs for all Americans. A statement for health professionals by the Committee on Exercise and cardiac rehabilitation of the Council on Clinical Cardiology, American Heart Association. Circulation 1996; 94: 857-862.

38. Sallis J, Hovell M, Hofstetter C. Predictors of adoption and maintenance of vigorous physical activity in men and women. Prev Med 1992; 21: 237-251.

39. Smith KM, Arthur HM, McKelvie RS, Kodis J. Differences in sustainability of exercise and health-related quality of life outcomes following home or hospital-based cardiac Rehabilitation. Eur J Cardiovasc Prev Rehabil 2004; 11: 313-319.

40. Marchionni N, Fattirolli F, Fumagalli S, Oldridge N, Del Lungo F, Morosi L, Burgisser C, Masotti G. Improved exercise tolerance and quality of life with cardiac rehabilitation of older patients after myocardial infarction: results of a randomized, controlled trial. Circulation 2003 6; 107: 2201-2206.

41. Sparks KE, Shaw DK, Eddy D, Hanigosky P, Vantrease JC. Alternatives for cardiac rehabilitation patients unable to return to a hospital-based program. Heart Lung 1993; 22: 298-303.

42. Arthur HM, Smith KM, Kodis J, McKelvie R. A controlled trial of hospital versus home-based exercise in cardiac patients. Med Sci Sports Exerc 2002; 34: 1544-50.

43. Jolly K, Lip GY, Sandercock J, Greenfield SM, Raftery JP, Mant J, Taylor R, Lane D, Lee KW, Stevens AJ. Home-based versus hospital-based cardiac rehabilitation after myocardial infarction or revascularisation: design and rationale of the Birmingham Rehabilitation Uptake Maximisation Study [BRUM]: a randomised controlled trial [ISRCTN72884263]. BMC Cardiovasc Disord 2003; 3: 10.

44. Ades PA, Pashkow FJ, Fletcher G, Pina IL, Zohman LR, Nestor JR. A controlled trial of cardiac rehabilitation in the home setting using electrocardiographic and voice transtelephonic monitoring. Am Heart J 2000; 139: 543548.

45. Henderson I, vanLohuizen K, Fenske T. Remote cardiac rehabilitation. J Telemed Telecare 2000; 6: S28-30.

46. Carlson J, Johnson J, Franklin B, Van der Laan R. Program participation, exercise adherence, cardiovascular outcomes, and program cost of traditional versus modified cardiac rehabilitation. Am J Cardiol 2000; 86: 17-23.

47. DeBusk RF, Haskell WL, Miller NH, Berra K, Taylor $\mathrm{CB}$, Berger WE 3rd, Lew H. Medically directed at-home rehabilitation soon after clinically uncomplicated acute myocardial infarction: a new model for patient care. Am J Cardiol 1985; 55: 251-257. 